\title{
The Effect of Nanokaolinite on the Compressibility and Atterberg Limit of the Silty Loess Soil in Golestan Province
}

\author{
Rasool Yazarloo ${ }^{1}$, Javad Gholizadeh ${ }^{1}$, Abdolghader Amanzadeh ${ }^{1}$, Seyed Aghil Mortazavi ${ }^{2}$ \\ ${ }^{1}$ Shams Institute of Higher Education, Department of Civil Engineering \\ Shadi st., Gonbad Kavoos, Iran \\ r.yazarloo@modares.ac.ir; j.gholizadeh@iauf.ac.ir; a_aman@iaug.ac.ir \\ ${ }^{2}$ Islamic Azad University of Ferdows, Department of Civil Engineering \\ Azadi st., Ferdows, Iran \\ seyed.mor@iauf.ac.ir
}

\begin{abstract}
The loess in Golestan Province can be divided into clayey, silty and sandy loess based on the geological engineering properties. The silty loess has great importance due to the extended surface and the several reported risks. Loess soil is one of the problematic soils in which some of the geotechnical properties should be modified or improved before conducting the projects. Loess is one of the soil types available in many countries and a great number of geotechnical risks were reported regarding them. The current study investigated the effect of adding nanokaolinite on the compressibility and the Atterberg limit of the silty loess soil of Golestan province through the field sampling and performing tests with the different percent of nanokaolinite. To prepare the nanokaolinite, the mechanical method of ball milling was employed. According to the grain size distribution tests, the soil sample is CL-ML type based on unified classification. Standard proctor test results showed that adding the nanokaolinite increased the maximum dry unit weight of the soil at first and then it was decreased. Moreover, adding nanokaolinite resulted in the significant increases of liquid and plastic limits while nanokaolinite amount more than $5 \%$ led to the decrease in plastic index.
\end{abstract}

Keywords: Nanokaolinite, Silty loess soil, Compressibility, Atterberg limit, Golestan province

\section{Introduction}

Loess is a homogeneous Aeolian deposit that is a well-sorted and porous material with light beige or brown color. The loess particles are mostly in size of a silt with a little clay or sand in some cases. These depositions are identified with the lack of layering and sorting in the field. The composition of loess mainly contains quartz, feldspar, calcite, dolomite, mica, iron and magnesium-bearing minerals and clayey minerals. In addition to the cement clay and calcium carbonate available in the loess, the salts may appear in the solid and semi-solid form on the surface of particles. Due to the chemical weathering of iron minerals in the loess, they are seen in yellow and brown color. This type of soils has been seen in different provinces of Iran such as Golestan, Markazi, Fars, Khuzestan and some others. Considering the population growth and urban development followed by building different structures and infrastructures on this type of soils with a change in their humidity, it is necessary to conduct more studies in order to understand and improved the structure on the loess. Moreover, the loess has low density and high voids in that their porosity decreases with saturation and the soil indicates high settlement under its own weight and without any loading (or under low loading rate). Loess can be categorized under the collapsible soil classification existing in many parts of Iran. The sudden decrease of soil volume during the saturation can be resulted in many structural hazards. The collapsible soils indicate high strength in low degree of saturation because of the intergranular bonds and honeycomb microstructures. However, the intergranular bonds (ex. they are a type of salt bonds in the loess soil) suddenly become weak when the water content increases. Therefore, the structure of soil suddenly collapses.

Different risks such as collapsibility, subsidence, divergence, high erosion and landslides are reported in the loess of Golestan [1]. Most of the soil in this site is not ideal for construction from an engineering perspective and they should be prepared for construction activities by applying some ground improvement techniques. One of the most 
recent methods for improvement of the problematic soils in geotechnical engineering is changing the properties of the soil in the site with nanomaterials [2].

The amazing effect of nanotechnology and its incredible function in this field were not noticed due to its complexity complexity and the macroscopic view of the most of the engineers and geotechnical researchers. Moreover, the studies in nontechnology are interdisciplinary and they include various range of subjects in chemistry (catalyzing the nanoparticles) and laser physics (quantum points). Therefore, the researchers need more specialized knowledge in a particular subject because they should understand the wide requirements of the nanotechnologies in order to provide effective participation in the field.

Most of the nanomaterials used for changing the geotechnical properties of the soils are silica nanoparticles affecting the consolidation properties, permeability and strength parameters of the soils. The silica nanoparticles were used for increasing the adhesion and cohesion between soil particles by Gallagher and Mitchell [3]. They improved the sand behavior by using the nanoparticles in the laboratory experiment under cyclic loading condition. Accordingly, Gallagher and Mitchell (2005) found that the adhesion and cohesion between soil particles increase depending on the nanoparticles percentage. Zhang [4] indicated that the nanostructures in the soil led to the increase in Atterberg limit. It is worth to mentioning that studies on Loess was started by Leonard in 1820. Recently, Lee [5] evaluated the liquefaction potential of loess by studying their microstructures.

Sarokalaei [6] investigated the effect of adding common nanomaterials such as nanosilica and nanoaluminum to the loess soil in order to find the best mixture percentage of these materials with the loess for improving its uniaxial strength. Khosravani [7] studied the effect of adding nanoclay to silty clay in Rasht city and observed that the plastic limit of the soil had a little increase but the liquid limits and plastic index had a considerable increase. Moreover, it was found that adding nanoclay led to the increase in the uniaxial strength and also in the resistance against the deformation of the studied soil. According to Qazi et al. [8], the modified montmorillonite nanoclay (MMN) significantly increased the liquid limit and the plastic index of the soil. In addition, adding $8 \% \mathrm{MMN}$ to the clay increase the plastic index for about 68 percent that can be effective in embankment dams with clayey core. They also investigated the impact of different MMN amounts on the uniaxial compressive strength of the clay and the results indicated that this parameter had a significant increase. Accordingly, the unconfined compressive strength increased by MMN increment, and it was improved to the maximum of 34.2 percent compared with the original soil. Also, Zhang [4] found that the existence of nanostructures in the soil increased the Atterberg limit.

Moreover, Gallagher [3] studied the effects of nanoparticles on the beginning of the liquefaction after the earthquake loads by conducting the dynamic triaxial tests. Other studies also found an increase in the Atterberg limits followed by adding the nanoparticles to the soil [4]. Based on the study about the reinforcing effect of nanoparticles, Zhang [4] concluded that adding the nanoparticles to the soil constantly increased the strength of the samples. The nanoclay has been also used in the concrete in order to investigate the permeability and uniaxial strength of the samples with $1 \%$ and $2 \%$ percent of nanoclays and samples without nanoclays [9]. Accordingly, Patel [9] found that the permeability in the samples with $1 \%$ and $2 \%$ of nanoclays are $150 \%$ and $200 \%$ higher than the samples without nanoclay. Also in the same condition, the samples with nanoclay are dried earlier and have higher compressive strength.

Taha and Yung [10] did research on the effect of nanocarbon tube on the basic geotechnical properties of Kaolinite. They conducted uniaxial and Atterberg limit tests on the samples without nanoparticles and with $1 \%$ and $2 \%$ of nanoparticles. The results indicated that the uniaxial compressive strength and Atterberg limit of the sample increased with adding the nanoparticles. Also the standard proctor and Atterberg limits tests were employed to investigate the effect of nanoclay on the basic geotechnical properties of the clay. They used the kaolinite clay in their studies based on the type CL unified classification. This type of soil has low plastic index, therefore different nanoclay percent were used to increase the plasticity of the soil. Moreover, Taha and Yung [10] built and tested the samples containing 1\%, 2\%, 4\% and 8\% of nanoclay by using montmorillonite clay. Based on the results of the studies, the increased water absorption, the flexibility of the sample (due to the increase in the specific surface of the samples) and electrical change were observed after adding the nanoclay. Accordingly, the permeability of the samples is anticipated to be decreased by the increase in flexibility (plasticity) and these properties are important at the core of earthdams.

The current study aims at finding the optimum percentage of the mixture of nanokaolinite and silty loess soil in Golestan province. To this end, the standard proctor and Atterberg limit tests were conducted on the single-day samples containing $0.5,1,1.5,2,3$ and $4 \%$ of nanokaolinite compared to the dry weight of the soil.

\section{Materials and Methods}




\subsection{Silty Loess Soil}

The studied soil is a type of silty loess soil, which was taken from Kalaleh city in Golestan province. The grain size distribution curve with the hydrometer test on this soil was illustrated in figure 1.

Table 1: The physical properties of the studied soil.

\begin{tabular}{|c|c|c|c|c|c|c|c|}
\hline Color & $\begin{array}{c}\text { Soil } \\
\text { classification }\end{array}$ & $\begin{array}{c}\text { Density } \\
(\mathrm{Gs})\end{array}$ & $\begin{array}{c}\text { Liquid } \\
\text { limit }\end{array}$ & $\begin{array}{c}\text { Plastic } \\
\text { limit }\end{array}$ & $\begin{array}{c}\text { Plastic } \\
\text { index }\end{array}$ & $\begin{array}{c}\text { Dry unit } \\
\text { weight } \\
\left(\mathbf{g r}^{\mathbf{g}} \mathbf{c m}^{\mathbf{3}}\right)\end{array}$ & $\begin{array}{c}\text { Water } \\
\text { content } \\
(\%)\end{array}$ \\
\hline Beige & CL-ML & 2.67 & 26 & 19 & 7 & 1.97 & 12.1 \\
\hline
\end{tabular}

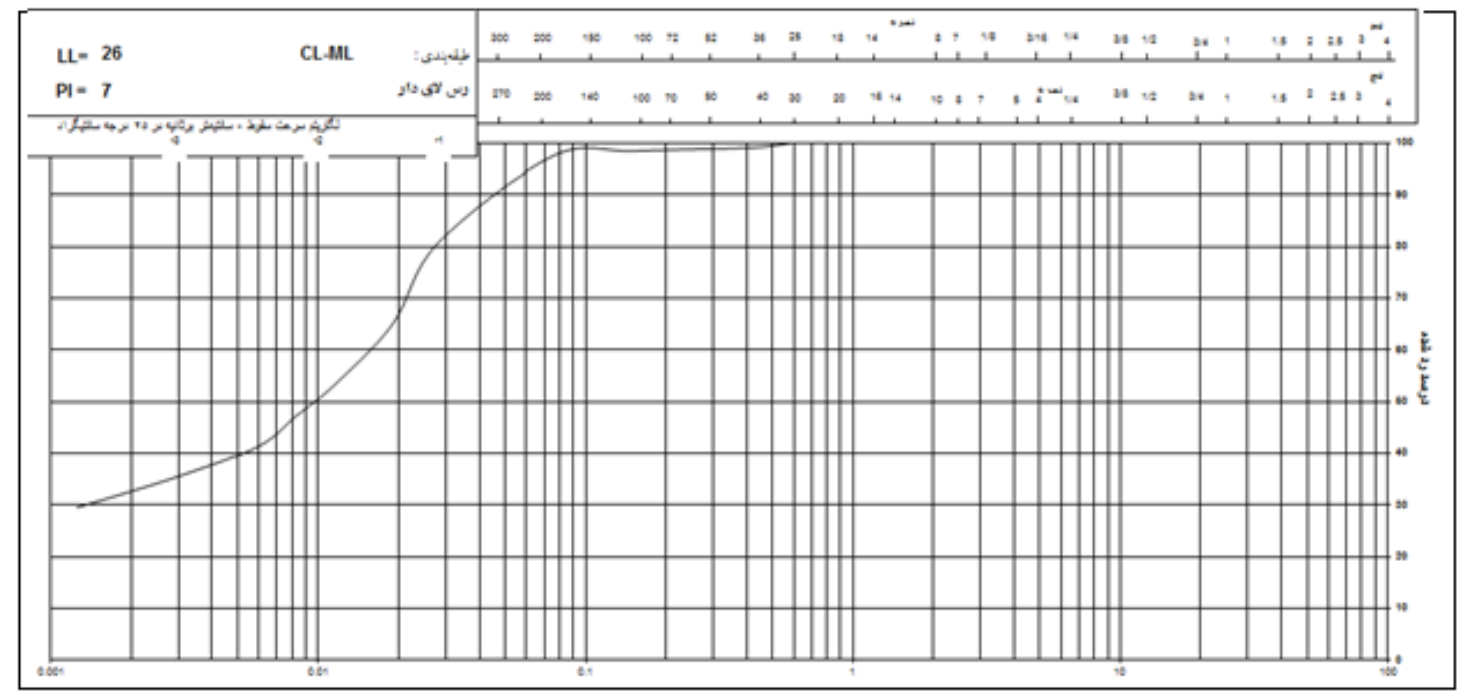

Fig. 1: The grain size distribution curve of the studied soil.

According to the tests, the studied soil was the CL-ML type (silty clay) based on the unified classification system. The results of the physical tests on the soil was provided in Table 1 and the results of the XRF test was depicted in

Table 2.

Table 2: The chemical composition of the studied silty loess soil based on XRF test result.

\begin{tabular}{|c|c|c|c|c|c|c|c|c|c|c|c|}
\hline $\mathbf{P}_{205}$ & Mno & Tio2 & $\mathrm{Na}_{2} \mathrm{O}$ & So3 & $\mathbf{K}_{2} \mathbf{0}$ & $\mathrm{Fe}_{2} \mathrm{O}_{3}$ & L.O.I & Cao & $\mathbf{A l}_{203}$ & $\mathrm{Sio}_{2}$ & Mixture \\
\hline 0.186 & 0.252 & .0437 & 1.450 & 4.069 & 4.431 & 4.817 & 9.38 & 9.418 & 13.642 & 50.854 & $\%$ \\
\hline
\end{tabular}

\subsection{Nanokaolinite}

Nanokaolinite was prepared by ball mill method and crushing mechanism. The microscopic image indicated that the particles reached nanometre scale through crushing process (Figure 2). The original kaolinite powder was provided by Tabriz tile factory which had very high purity (almost 99\%). The results of XRD and XRF tests on the original kaolinite and the derived nanoparticles indicated that there was no change in the chemical composition of the main powder through the crushing process. This is one of the advantages of the ball mill method to produce the nanoparticles. Figure 3 and table 3 illustrated the results of XRD and XRF tests on nanokaolinite respectively and table 4 showed the quantity of the effective parameters in nanoparticles production by the ball mill machine. 


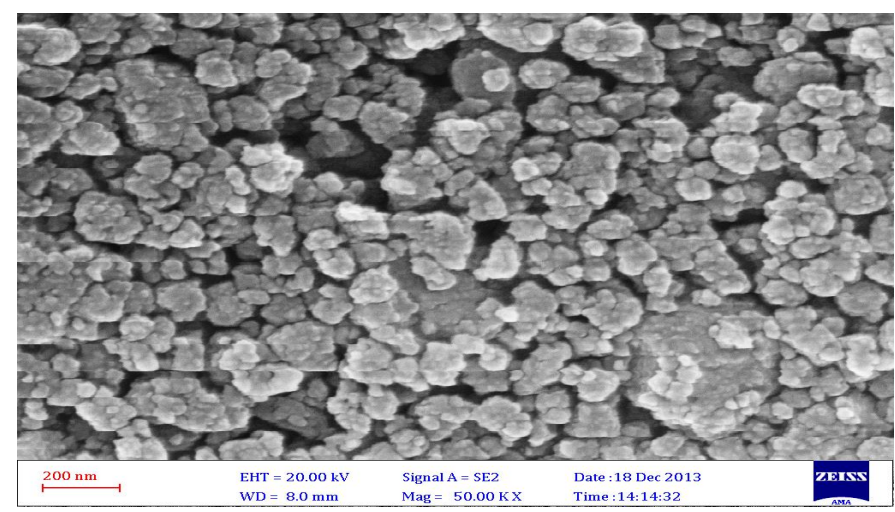

Fig. 2: The FESEM nanokaolinite image prepared from the ball mill method.

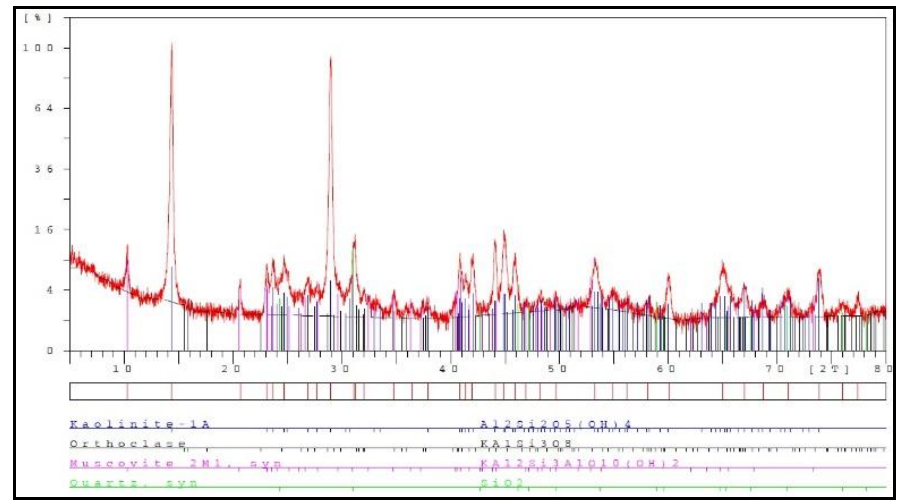

Fig. 3: The results of XRD on the nanokaolinite.

Table 3: The results of XRD on the nanokaolinite.

\begin{tabular}{|c|c|c|c|c|c|c|}
\hline Mgo & Cao & $\mathrm{K}_{2} \mathrm{O}$ & L.O.I & $\mathrm{Al}_{2} \mathrm{O}_{3}$ & Sio $_{2}$ & Traces \\
\hline 0.343 & 1.054 & 3.446 & 2.87 & 31.228 & 41.158 & F,Na,Ti,Mn,Ni \\
\hline
\end{tabular}

Table 4: The used condition for the machine functioning to prepare the nanokaolinite powder.

\begin{tabular}{|c|c|c|c|c|}
\hline Ball material & Ball size & Mill time & Spinning speed & Parameter \\
\hline Steel & $\begin{array}{c}\mathbf{1 0} \text { balls } / \mathbf{1 0} \mathbf{~ m m} \\
\mathbf{1 5} \mathrm{balls} / \mathbf{1 5} \mathrm{mm}\end{array}$ & $\mathbf{1 0}$ hours & $\mathbf{5 2 0} \mathrm{Rpm}$ & $\begin{array}{c}\text { Parameter } \\
\text { quantity }\end{array}$ \\
\hline
\end{tabular}

\subsection{Samples Preparation Method}

The modified proctor test (based on ASTM-D1557) was conducted on the dry soil by A-method with 0.5, 1, 1.5, 2, 3 and 4 nanokaolinite percent compared to the dry weight of soil. The test was used to determine the maximum dry unit weight and the percentage of optimum water content. To perform the modified proctor test, first, the soil was dried and passed through $19 \mathrm{~mm}$ sieve. Then five samples of the $2.3 \mathrm{Kg}$ weight soil were prepared and the nanokaolinite was added to the soil. Next, the mixture of soil and nanomaterial were mixed in a blending machine with low speed for at least 15 minutes. After this step, some water was added to the sample and it was kept in a plastic container to provide an opportunity for the chemical reaction with the soil composition for 24 hours. Finally, the proctor test was conducted in 5 separate stages on 5 layers. Moreover, each layer was compacted with 25 hits (hammer size of 4-inch) with a 10-pound proctor hammer from an 18-inch falling height. This test was done completely and separately for each nanokaolinite percent.

To conduct the Atterberg limits test, first, the soil was dried and passed through the sieve No.40. Second, 40 percent of the required nanokaolinite $(0.5,1,1.5,2,3,4,5$ and 8$)$ was added to soil based on the weight of the passing soil. Then the 
mixture of soil and nanomaterial were mixed in the blending machine with low speed for at least 15 minutes. After this, some water was added to the sample and it was kept in a plastic container to provide an opportunity for the chemical reaction with the soil composition for 24 hours. Then the liquid limit test (based on ASTM D4318) and single-point method were conducted for all nonopercent completely and separately. In addition, each liquid limit test was performed by a plastic limit experiment (based on the same standards) by rolling the soil on glass surface. The results of this test were provided in the next section.

\section{Test Results}

Figure 4 indicated the chart for the maximum dry unit weight with respect to different nanokaolinite percentage and the figures 5, 6 and 7 illustrated the charts for changes of liquid limits, plastic limit and plastic index based on the different percent of nanokaolinite for single-day samples. According to figure 4, adding the nanokaolinite up to $2 \%$ resulted in the increase in the dry unit weight in the silty loess soil particles, which can be due to the replacement of nanokaolinite particles in the tiny holes of the soil instead of water. However, the high increment of nanoparticle can result in aggregation and agglomeration of the nanokaolinite particles and the excessive increment of the optimum percentage $(2 \%)$ led to decrease in dry unit weight. Moreover, the area under the proctor curve indicated that the increase in nanokaolinite percent led to the increase in the area under this curve. These increments were the sign of more water absorption by the soil and also an increase in the optimum percent of water content influenced by the nanokaolinite.

Considering the very small size of nanokaolinite, they can penetrate into the natural nanocavities in the soil structure. Therefore, this can be because of the change in liquid and plastic limits of soil following the mixing with nanomaterials. The results revealed that the increasing trend of the plastic limit and the liquid limit is almost same. With regard to the plastic index formula (PI=LL-PL), the plastic index in the lower percent of nanokaolinite was almost constant and when the nanokaolinite in the silty loess composition was increased by 5\% (or more) the plastic index is decreasing (figure 7). The decrease in the plastic index was a good phenomenon for geotechnical engineering for weak soil improvement in civil projects, but the excessive use of nanokaolinite should be investigated considering its price and the economic issue.

Moreover, for a liquid limit of the soil, the linear relationship of $L L=1.7673 \mathrm{Nano} \%+26.091$ (figure 5) and for a plastic limit of the soil, the linear relationship of $\mathrm{PL}=2.111 \mathrm{Nano} \%+18.581$ (figure 6) were acceptable in the nanokaolinite between 0 to 8 percent. It was observed that in the nanokaolinite percent of $0.5,1$ and 1.5 , the soil was CL-ML type based on the unified classification system and in the nanokaolinite percent of 2,3,4,5 and 8, the studied soil was changed to ML type based on the unified classification system.

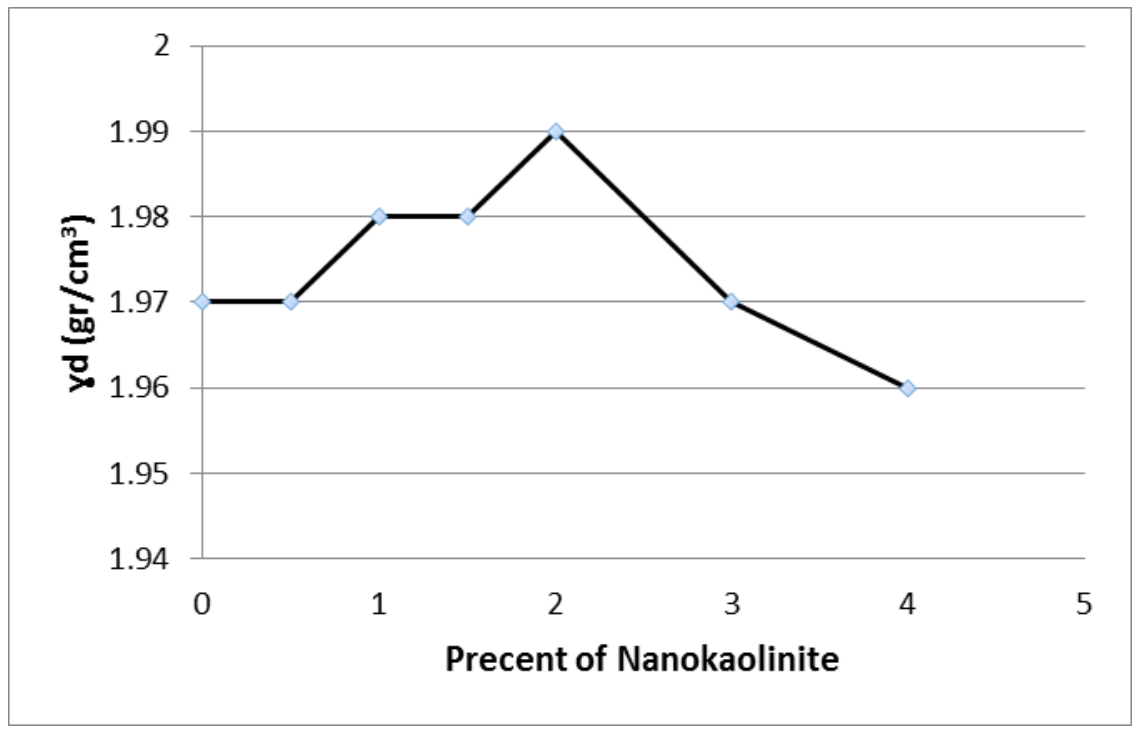

Fig. 4: The curve of the nanokaolinite effect on the maximum dry unit weight of soil. 


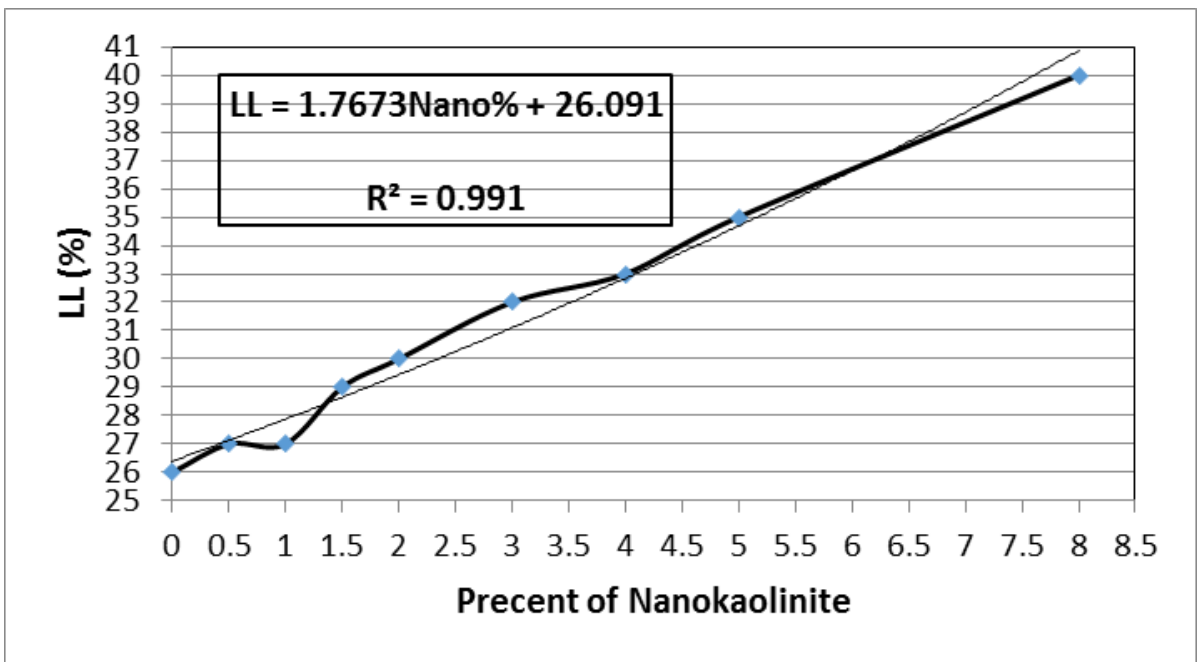

Fig. 5: The curve of the effect of nanokaolinite on the liquid limit of the studied soil.

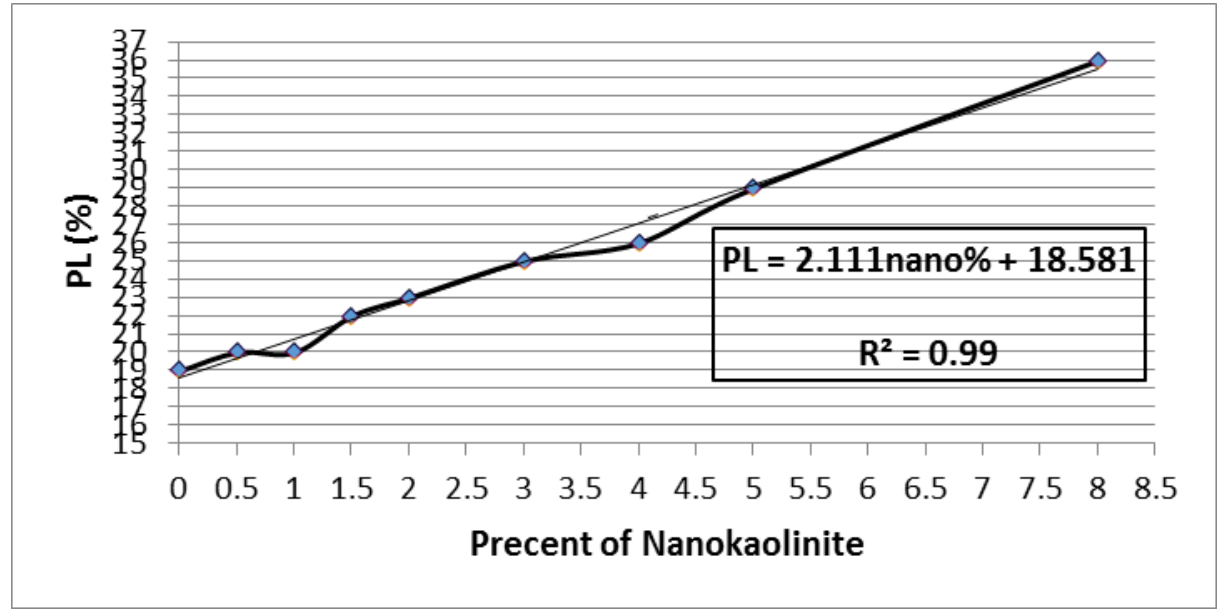

Fig. 6: The effect of the nanokaolinite on the plastic limit of the studied soil.

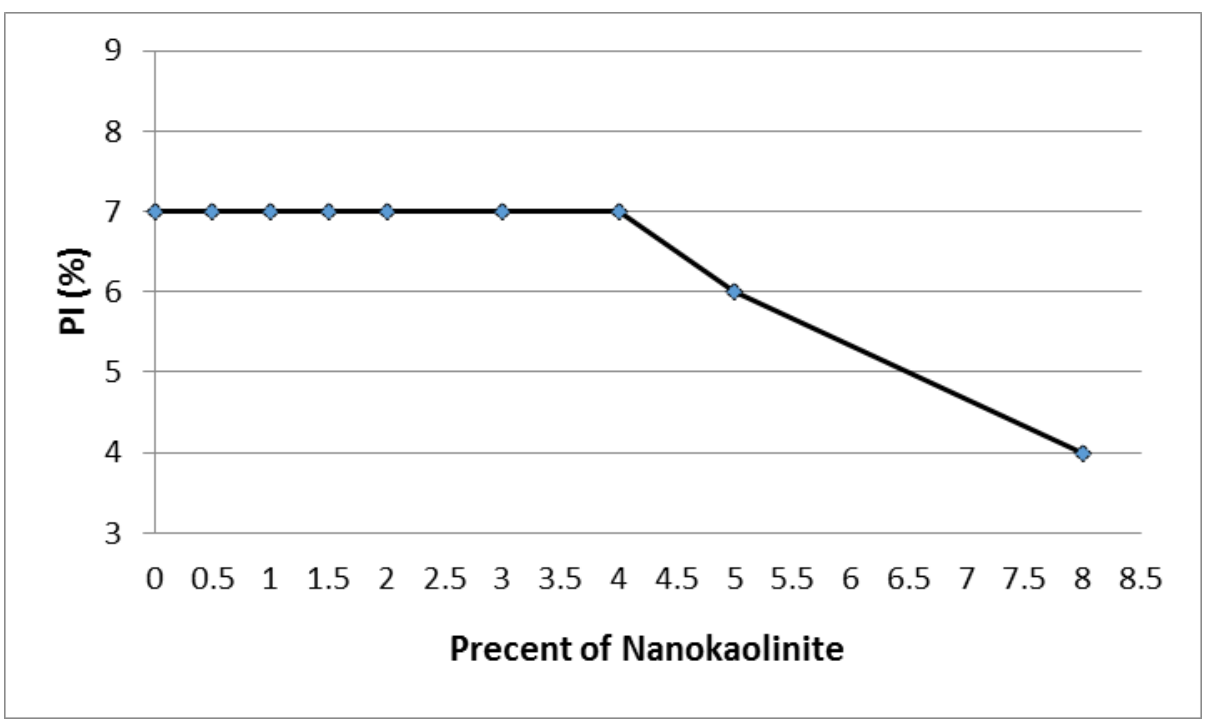

Fig. 7: The curve of the effect of nanokaolinite on the plastic index of the studied soil. 


\section{Conclusion}

In this paper the effect of nanokaolinite on compressibility and Atterberg limits of silty loess of Golestan province in north-east of Iran has been studied. The main obtained results can be summarized as follow: is $2 \%$.

A. The results indicated that in proctor test the optimum percent of nanokaolinite compared to the dry soil weight

B. According to the modified proctor tests, adding the nanokaolinite up to $2 \%$ of the dry soil weight to the silty loess soil of the Golestan province increased the maximum unit weight of the soil. After the $2 \%$, the maximum unit weight started to decrease and the optimum percent of soil water content increases by adding nanokaolinite. Moreover, the area under the proctor test curve increases by increasing the nanokaolinite. It can be due to the replacement of the nanokaolinite particles in the tiny holes of the soil instead of air or water. However, the excessive increment can result in aggregation and agglomeration of the nanokaolinite particles. Moreover, the excessive increment of the $2 \%$ optimum led to the maximum unit weight increase.

C. The findings of the Atterberg limit tests showed that the increment in the nanokaolinite amount in the silty loess soil of the Golestan province increased the liquid limit and plastic limit. But the plastic limit was constant in the lower percent and the degree of the plastic index showed more decrease after adding 5\% nanokaolinite. This is desirable in engineering applications, but considering the consumption and price of nanoparticles, the use of nanoparticles for decreasing the plastic index should be closely investigated by experts.

D. By increasing the nanokaolinite in the soil, the liquid limit and plastic limit of the soil were increased. One probable reason of this increment can be the higher level of the surface to volume of nanokaolinite (specific surface) or the high reactivity of nanokaolinite with water. Moreover, considering the small size of nanokaolinite, this material can penetrate into the natural nanocavities in the soil structure. Therefore, this property can be another reason for the change in liquid and plastic limits of soil through the combination with nanomaterials.

\section{References}

[1] H. Rezaiy, G. R. Lashkaripour, M. Ghafouri, and N. H. Moghaddas, "A Comparative Study of the Preliminary Examining Methods for Liquefaction Potential and Geological Conditions of Coastal Soils in the Southeastern Caspian Sea," Research Journal of Environmental Sciences, vol. 5, no. 4, pp. 329-341, 2011.

[2] Plan and Budget Organization of Golestan Province, in 2010, indicators of population, housing, Iran's Statistics Center.

[3] P. M. Gallagher, Y. Lin, "Column Testing to Determine Colloid Silica Transport Mechanisms," in Sessions of the Geo-Frontiers Congress, 2005.

[4] G. Zhang, J. T. Germaine, A. J. Whittle, and C. C. Ladd, "Index properties of a highly weathered old alluvium," Geotechnique, vol. 54, no. 7, 441-451, 2004.

[5] K. M. Lee, P. C. C. Ng, "A geotechnical investigation of marine deposits in a nearshore seabed for land reclamation," Can. Geotech. J., vol. 36, no. 6, pp. 981-1000, 1999.

[6] B. Sarokalaei, "Investigation of the behavioral feature and strength of the loess soils registered with the nanoparticles: a case study of Gorgan," The M.Sc. published the thesis in the industrial university of Isfahan, Department of Civil Engineering, 2012.

[7] A. Khosravani, \& A. Qorbani, "Investigating the effect of nanoclay on the engineering properties of the cohesive soils," The sixth national conference in civil engineering studies, 2011.

[8] H. Qazi, M. H. Baziar, S. M. Mirkazemi, "Investigating the effect of adding nanoclay on the basic geotechnical engineering properties of the soil," The fourth international conference on geotechnical engineering and soil mechanics in Iran, 2010.

[9] K. Patel, "The Use Of Nanoclay As A Constructional Material," International Journal of Engineering Research and Applications, vol. 2, no. 4, pp. 1382-1386, 2012.

[10] M. R. Taha and T. Ying, "Effects of carbon nanotube on kaolinite:Basic geotechnical behaviour," Proc. of the 5rd international symposium on nanotechnology in construction, Prague, Czech Republic, pp. 377-382, 2012. 